\title{
Endodoncia preventiva: Protección pulpar mediante la técnica de eliminación de la caries en etapas (stepwise excavation)
}

\section{Preventive endodontics: pulp protection using stepwise caries removal procedure}

\author{
Castellanos-Cosano L*, Martín-González J*, Calvo-Monroy C*, López-Frías FJ*, \\ Velasco-Ortega E**, Llamas-Carreras JM*, Segura-Egea JJ*
}

\begin{abstract}
RESUMEN
El tratamiento de la caries dentinaria profunda en dientes permanentes se ha venido realizando, generalmente, mediante la remoción completa y en una sola sesión de la dentina cariada, incluyendo la dentina blanda desmineralizada, sin tener en cuenta el potencial regenerador de la pulpa dental. Una complicación frecuentemente ligada a esta actitud es la exposición pulpar intraoperatoria que, en muchos casos, termina en tratamiento de conductos. Varios estudios han demostrado que la eliminación de la caries dentinaria profunda por etapas, en dos visitas con varios meses de diferencia, protege a la pulpa, disminuyendo la frecuencia de exposiciones pulpares, a la vez que permite la formación de dentina terciaria, con la consiguiente disminución del porcentaje de casos que requieren tratamiento endodóncico. En este artículo se analiza el estado del conocimiento y la evidencia científica sobre este tema.
\end{abstract}

Palabras clave: Caries, dentina reactiva, dentina reparativa, dentina terciaria, dentinogénesis, endodoncia preventiva, pulpa dental, recubrimiento pulpar.

\section{SUMMARY}

The treatment of deep dentine carious lesions in permanent teeth has included, generally, complete removal of affected dentin in a single session, including soft demineralized dentin, regardless of the regenerative potential of dental pulp. One complication often linked to this attitude is the pulp exposure, in many cases ending in root canal treatment. Several studies have shown that the elimination of deep dentine caries in stages, in two visits to several months apart, protects the pulp, reducing the frequency of pulp exposures, while allowing the development of tertiary dentin, with the consequent decrease in the percentage of cases requiring endodontic treatment. This article discusses the state of knowledge and scientific evidence on this topic.

Key words: Dental caries, dental pulp, dentinogenesis, preventive endodontics, pulp capping, reactionary dentin, reparative dentin, stepwise excavation.

Fecha de recepción: Diciembre de 2010.

Aceptado para publicación: Diciembre de 2010.

* Grupo de Investigación en Endodoncia CTS-941. Departamento de Estomatología. Universidad de Sevilla. Sevilla. España.

** Departamento de Estomatología. Universidad de Sevilla. Sevilla, España.

Castellanos-Cosano L, Martín-González J, Calvo-Monroy C, López-Frías FJ, Velasco-Ortega E, Llamas-Carreras JM, Segura-Egea JJ. Endodoncia preventiva: Protección pulpar mediante la técnica de eliminación de la caries en etapas (stepwise excavation). Av. Odontoestomatol 2011; 27 (5): 245-252. 


\section{INTRODUCCIÓN}

El diente representa la cumbre de la evolución filogenética en lo que al desarrollo de tejidos mineralizados se refiere. El esmalte dentario, con un 96$97 \%$ en peso de materia inorgánica, y la dentina, con el $70 \%$ en peso, son los tejidos de mayor contenido mineral (1). El esmalte es resultado de la actividad ameloblástica y, dado que los ameloblastos desaparecen una vez termina su función, es un tejido acelular, sin capacidad de respuesta ante las agresiones. Por el contrario, la dentina es producida por los odontoblastos, células que persisten en la pulpa y mantienen su capacidad dentinogénica durante toda la vida, dotando al complejo dentinopulpar de capacidad de respuesta frente a los agentes agresivos.

La dentina formada durante el desarrollo dentario hasta la completa formación de la raíz se denomina dentina primaria y comprende la dentina del manto y la porción principal de la dentina circumpulpar. La dentina sintetizada de forma fisiológica por el odontoblasto tras la completa formación de la raíz recibe el calificativo de secundaria y su formación tiene lugar durante toda la vida, siendo el resultado de la función secretora del odontoblasto una vez terminado el desarrollo dentario. La dentina secundaria se forma más lentamente que la primaria y se deposita en la superficie interna de la cámara pulpar y de los conductos radiculares, pero de forma asimétrica, oponiéndose especialmente en el techo y en el suelo de la cámara pulpar, provocando una progresiva disminución del volumen de la cavidad pulpar. Los túbulos dentinarios de la dentina primaria se continúan con los de la secundaria, demostrando que es el mismo odontoblasto el responsable de la formación de los dos tipos de dentina.

Las diferencias en el proceso de formación de las dentinas primaria y secundaria repercuten también en sus estructuras. La dentina primaria tiene una estructura tubular regular, distinguiéndose la dentina peritubular, altamente mineralizada y con una matriz rica en proteínas no colágenas, y la intertubular, con mayor proporción de colágena en su matriz (2). La estructura de la dentina secundaria es similar a la de la primaria, aunque su trama tubular está menos desarrollada.
Como consecuencia de la aposición de dentina peritubular durante el trascurso de la vida, los túbulos dentinarios se van cerrando hasta ocluirse por completo, lo que es un hallazgo característico de la dentina vieja o dentina esclerótica (3). Estímulos agresivos tales como la caries o la atrición provocan la esclerosis acelerada de la dentina subyacente al lugar de acción del estímulo. La dentina esclerótica es fácilmente identificable en cortes histológicos debido a su translucidez, consecuencia de la homogeneidad estructural de esta dentina al estar muy mineralizados tanto la matriz como los túbulos. La esclerosis provoca una disminución de la permeabilidad dentinaria, protegiendo a la pulpa frente a los agentes irritantes.

\section{RESPUESTA DEFENSIVA PULPAR ANTE LA AGRESIÓN: DENTINOGÉNESIS TERCIARIA REACTIVA Y REPARATIVA}

Cuando el complejo dentino-pulpar se ve afectado por la caries o por traumas mecánicos, físicos o químicos, la patología pulpar que se desarrolla es consecuencia del entramado formado por la respuesta inflamatoria de las células pulpares, la microcirculación y la acción de los neuropéptidos pulpares (4-6). La vasodilatación y el edema consecutivo a la reacción vascular inicial que caracteriza a la respuesta inflamatoria, tienen lugar en el interior de una cámara pulpar rígida e inextensible, por lo que la presión hidrostática tisular se incrementa y los capilares pulpares son comprimidos hasta su colapso. A pesar de que el incremento de la presión hidrostática intrapulpar provocado por los agentes agresores antes citados suele ser un fenómeno localizado (7) y los sistemas de «feedback» la revierten generalmente a sus niveles normales, con frecuencia la exacerbación de la agresión inicial provoca una afectación tisular irreversible y generalizada, conocida como pulpitis irreversible, que desemboca en la necrosis pulpar.

Estudios recientes plantean una nueva interpretación de la respuesta pulpar frente a la agresión que supone el avance de la caries en la dentina, donde la respuesta pulpar se produciría desde el inicio mismo de la lesión cariosa dentinaria, ya que la pulpa reaccionaría a las señales que le llegan a través del es- 
malte, incluso antes de que se observara reacción histológica en la dentina (8). Sin embargo, la precocidad de la respuesta no implica una afectación irreversible de la pulpa y, por tanto, un «punto de no retorno». Si las interacciones dinámicas entre el factor agresor, la reacción del sistema neurovascular pulpar y el estado estructural/funcional del tejido pulpar son favorables a la curación tisular, el potencial reparativo intrínseco de las células pulpares se manifiesta y se produce la reparación pulpar, representada en su grado máximo por la dentinogénesis terciaria reactiva y, de modo especial, por la dentinogénesis terciaria reparativa.

Denominamos «dentinogénesis terciaria» a la formación de dentina en determinados lugares de la interfase pulpa-dentina en respuesta a estímulos ambientales nocivos. La dentina terciaria se localiza, de forma característica, en los lugares de la cavidad pulpar subyacentes al de la acción del estímulo nocivo (9) (Fig. 1). Si los estímulos nocivos son de grado ligero o moderado no llegan a producir la muerte de los odontoblastos sino que, por el contrario, los estimulan incrementando su tasa de secreción de matriz dentinaria. A la dentina terciaria secretada por los odontoblastos frente a estímulos nocivos se la denomina dentina reactiva.

Sin embargo, cuando los agentes agresores han provocado la necrosis local del estrato odontoblástico, siempre que las condiciones del complejo dentino-pulpar sean favorables, se diferenciarán, a partir de las células mesenquimatosas indiferenciadas pulpares, células con capacidad dentinogénica a las que se denomina dentinoblastos, neo-odontoblastos $u$ odontoblastos secundarios (6). La dentinogénesis terciaria reparativa parece estar controlada por moléculas de la superfamilia TGF- $\beta$ (factor de crecimiento transformante beta), concretamente por el TGF- $\beta 1$ y la BMP-4, cuya expresión se incrementa gradualmente durante la diferenciación de las células pulpares en dentinoblastos, a la vez que los receptores específicos para estas moléculas (ALK-5 y T $\beta R$-II) son expresados en su membrana celular (7) (Fig. 2). Morfológicamente parecen odontoblastos primarios, alargados, con núcleo claro y polaridad citoplasmática y secretora, y se organizan en una capa, estrato neo-odontoblástico, que generalmente queda más separado de la neodentina que

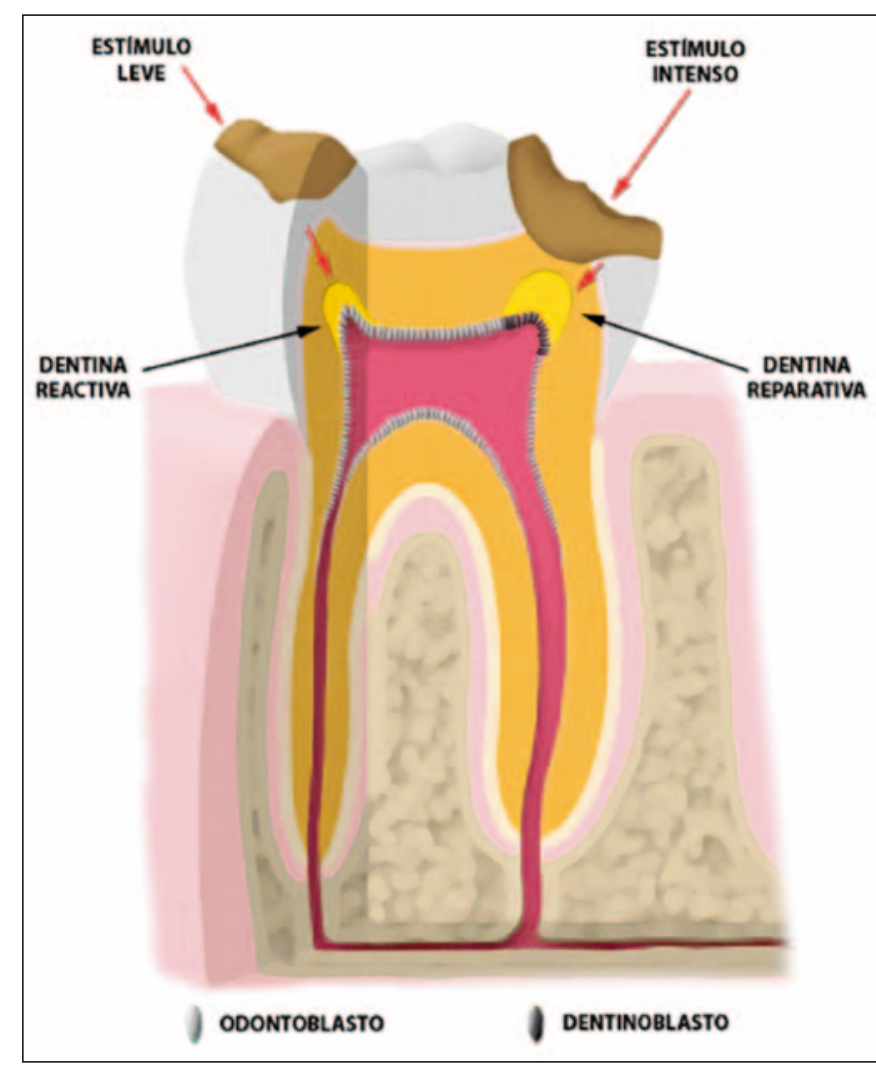

Fig.1. Respuesta pulpo-dentinaria frente a los estímulos agresivos: dentinogénesis terciaria reactiva y reparativa. La dentina reactiva es secretada por los odontoblastos post-mitóticos subyacentes al esmalte y/o dentina que sufren la agresión de un estímulo nocivo leve. Cuando el estímulo agresivo es intenso, los odontoblastos mueren y una nueva generación de dentinoblastos, provenientes de la diferenciación de células mesenquimatosas indiferenciadas, asume la función de formar dentina terciaria, denominada en este caso dentina reparativa.

los odontoblastos lo estaban respecto a la dentina. Los dentinoblastos pueden también originarse a partir de los fibroblastos pulpares y de las células perivasculares (7). A la dentina terciaria secretada por los neo-odontoblastos se la denomina dentina reparativa o neodentina $(6,9)$.

La estructura de la dentina terciaria, reactiva o reparativa, presenta un amplio espectro de variación que va desde una matriz regular tubular, virtualmente indistinguible de la de la dentina primaria, hasta una estructura distrófica, atubular, con células atrapadas e incluidas (tractos muertos), con gran deposición de dentina peritubular.

La dentinogénesis terciaria bajo las lesiones pequeñas de caries que avanzan lentamente es, básica- 


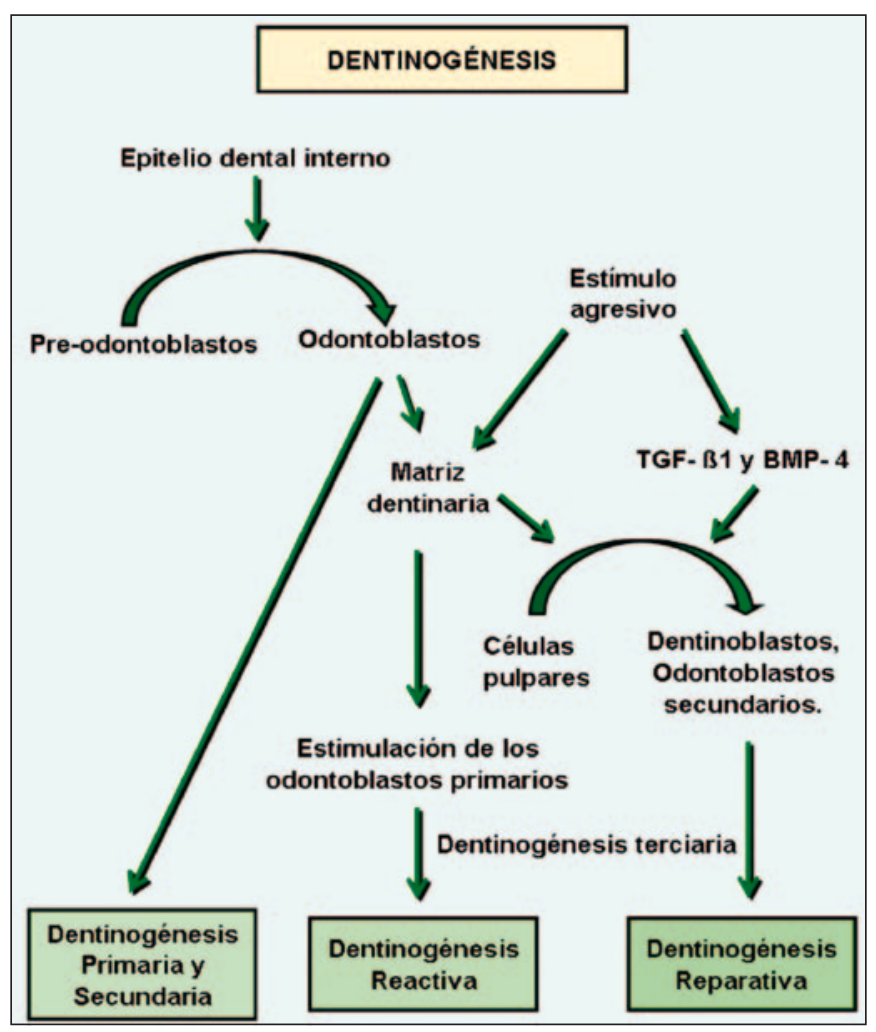

Fig. 2. Diferenciación de neo-odontoblastos (dentinoblastos) en respuesta a estímulos agresivos. Control por moléculas de la superfamilia TGF- $\beta$, concretamente el TGF - $\beta 1$ (factor de crecimiento transformante $\beta 1$ ) y la BMP - 4 (proteína morfogenética 4).

mente, reactiva. Por el contrario, en las lesiones mayores y más activas, la muerte de los odontoblastos primarios origina la formación de dentina reparativa. Pero incluso en las lesiones de progresión más lenta, la respuesta dentinaria suele conllevar la formación de ambos tipos de dentina terciaria. En definitiva, la dinámica de la lesión cariosa tiene una gran influencia en la naturaleza de la respuesta terciaria dentinogenética, siendo ésta un reflejo de los cambios producidos en la actividad de la lesión. Lógicamente, si el diente cariado se deja sin tratamiento, la lesión progresa y se produce la descomposición total del tejido $(8,10)$.

Bajo la lesión cariosa, la formación de dentina esclerótica y la hipercalcificación tubular no serían más que una manifestación de la dentinogénesis terciaria reactiva. Los túbulos se hipercalcificarían como resultado de la actividad fisiológica de los odontoblastos bajo una caries de progresión lenta, gracias a la reprecipitación de los cristales de hidroxiapatita de la dentina peritubular disueltos previamente por acción del pH ácido que conlleva el proceso carioso.

En ciertos casos, la dentinogénesis reparativa se produce sobre una matriz de fibrodentina (fibrodentinogénesis) (6). Fibroblastos, células endoteliales o células mesenquimatosas indiferenciadas de la pulpa central pueden emigrar hacia la región pulpar en la que se ha iniciado la dentinogénesis reparativa y diferenciarse en células pulpares cuboideas formadoras de dentina (11), denominadas pulpoblastos o fibrodentinoblastos, elaborando una matriz atubular de fibrodentina. Las células implicadas en la formación de fibrodentina apenas muestran diferencias ultraestructurales con las células mesenquimatosas indiferenciadas pulpares, no estando claro si se trata de una respuesta específica dentinogénica o de una reacción inespecífica del tejido conectivo pulpar. A veces el patrón de la fibrodentina formada es osteotípico, denominándosele osteodentina o dentina trabecular y a las células que lo originan osteodentinoblastos.

Si las condiciones del complejo dentino pulpar no son favorables y no intervienen los mecanismos de defensa descritos anteriormente, se produce la progresión de la caries activa, que se manifiesta con un aumento de la sensibilidad respecto al calor, al frío y a los dulces (pulpitis reversible). Si aún así, la caries no se trata, el proceso carioso termina por producir la infección de la pulpa y su inflamación irreversible (pulpitis irreversible), que conduce necesariamente a la necrosis pulpar y a su secuela, la patología periapical. El tratamiento endodóncico o la extracción dentaria, suelen ser las únicas alternativas que a menudo nos encontramos en la práctica odontológica y en diversos libros de texto, como solución a las lesiones cariosas profundas (8).

\section{DIAGNÓSTICO CLÍNICO DE LA CARIES}

El diagnóstico de la caries del esmalte no cavitada se realiza, fundamentalmente, mediante la inspección visual. Para ello los dientes deben estar limpios y secos y el campo debe estar perfectamente iluminado. La "mancha blanca" de la caries inicial del esmalte es más evidente cuando el esmalte está seco. La explicación radica en los diferentes índices de 
refracción (IR) que tienen el esmalte $(1,62)$, el agua $(1,33)$ y el aire $(1,0)$. Si los poros del esmalte desmineralizado (cariado) están llenos de agua, la diferencia de IR es $1,62-1,33=0,29$. Cuando los poros están llenos de aire (se ha secado la superficie dental) la diferencia de IR es 1,62-1,0=0,62 y la "mancha blanca" es mucho más evidente (12).

Cuando la caries ha alcanzado la dentina, es muy importante diferenciar entre caries activa y caries detenida. Los criterios clínicos para clasificar una caries dentinaria como activa son: presencia de tejido blando y desmineralizado, de color amarillo o amarrilloanaranjado que a simple vista parece estar húmedo. Mientras que la caries dentinaria detenida presenta un tejido duro a moderadamente blando, marrón oscuro y con apariencia seca. El cambio morfológico dentinario entre ambos procesos es claramente diferenciable (13). La progresión lenta de la caries puede terminar en una caries detenida. Así mismo, modificaciones en la higiene oral podrían favorecer el cambio de estado de caries activa a caries detenida (14).

La dentina cariada presenta dos zonas bien diferenciadas: una externa, a la que se denomina dentina infectada, y otra más interna, no infectada, la dentina afectada. En la dentina infectada la estructura histológica está completamente perdida. Los túbulos dentinarios están desorganizados y su interior está ocupado por bacterias que proliferan en su interior. Debido a la desmineralización que acompaña al proceso carioso la dentina peritubular desaparece y el diámetro tubular aumenta. Las bacterias van invadiendo la dentina intertubular, facilitado este hecho por la pérdida de la dentina peritubular, y los túbulos van coalesciendo unos con otros, dando lugar a la formación de áreas de necrosis. En la dentina intertubular se aprecia una desmineralización severa, las fibras de colágeno quedan expuestas total o parcialmente y están desnaturalizadas. Dado que no hay procesos odontoblásticos vivos y las fibras colágenas están irreversiblemente dañadas, esta dentina no se puede remineralizar, por lo que debe ser eliminada operatoriamente (15). Por lo que a la dentina afectada se refiere, la estructura dentinaria está conservada, pudiendo dividirse a su vez en tres zonas, del exterior al interior: capa túrbida, zona transparente o translúcida y zona subtransparente. En la capa túrbida los procesos odontoblásticos están presentes y vivos. La dentina peritubular ya sí es evidente y, aunque la dentina intertubular está desmineralizada, las fibras colágenas no están desnaturalizadas y presentan sus bandas características. Aunque se considera una capa libre de bacterias, hay autores que han demostrado su presencia. En la zona transparente o translúcida la dentina intertubular está parcialmente desmineralizada, conteniendo los túbulos dentinarios cristales de whithloquita, de gran tamaño y más resistentes al ataque ácido. Esta esclerosis tubular es la responsable de su aspecto transparente o translúcido. En esta zona, la permeabilidad dentinaria está reducida y, por tanto, el paso de ácidos, bacterias y productos bacterianos también, sirviendo de protección para el tejido pulpar. Sin embargo, aunque el interior de los túbulos está ocupado por cristales de whithloquita, es una dentina significativamente más blanda. Esto se debe a que su matriz intertubular está desmineralizada como consecuencia del proceso carioso y, las propiedades mecánicas de la dentina dependen de las de la dentina intertubular. En definitiva, es una dentina que debemos respetar durante la remoción de la caries. La dentina subtransparente no es más que una zona de transición entre la zona transparente y la dentina sana (16).

\section{TÉCNICA DE ELIMINACIÓN DE LA CARIES PROFUNDA POR ETAPAS}

La técnica de eliminación de la caries en etapas (TECE) (stepwise excavation) es utilizada en el tratamiento de las caries dentinarias profundas con el objetivo de preservar la pulpa. En una primera fase operatoria se eliminaría la dentina infectada y, tras un periodo de obturación provisional, se re-intervendría para acabar la eliminación de toda la dentina cariada y realizar la obturación definitiva.

Las revisiones llevadas a cabo por la Cochrane Collaboration sobre tratamiento de la caries y protección pulpar $(17,18)$, concluyen que la TECE en dientes asintomáticos reduce el riesgo de exposición pulpar y es de elección en las caries profundas, aunque no está claro si es necesario reintervenir.

El punto esencial para llevar a cabo la TECE es la definición de caries dentinaria profunda (Fig. 3). En 


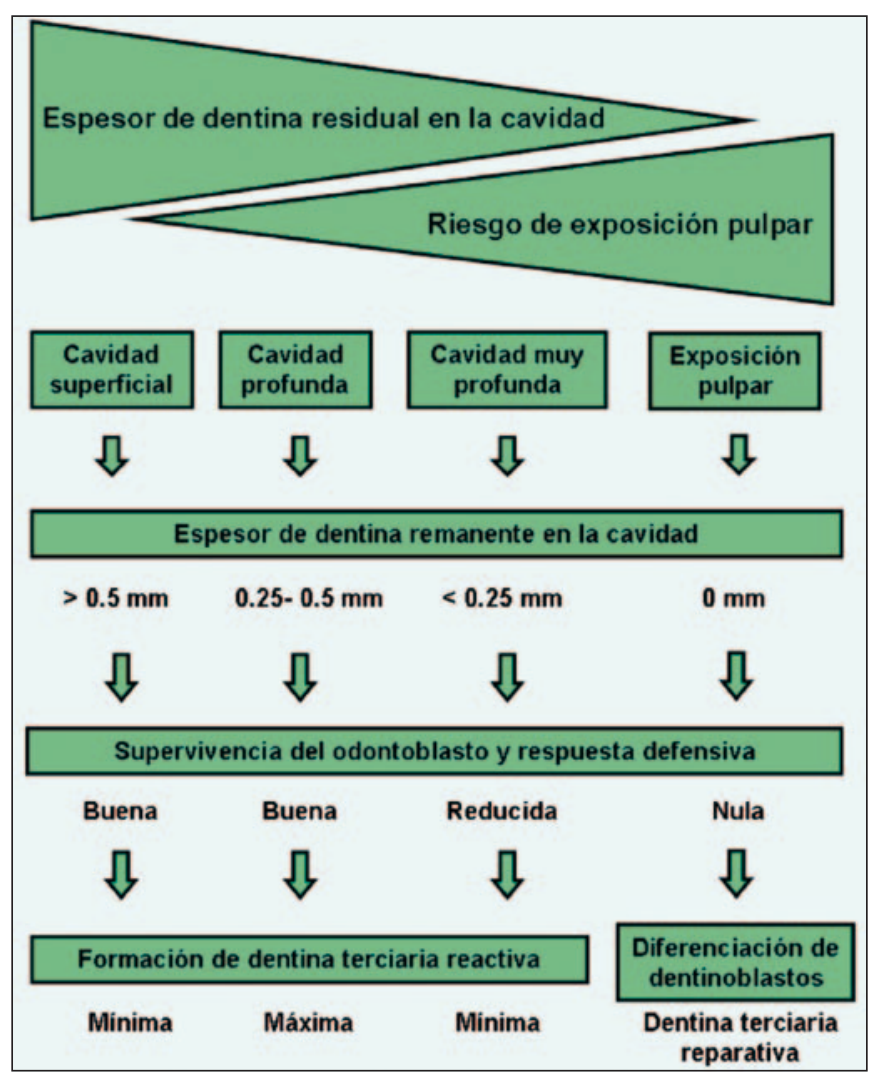

Fig.3. Relación entre el espesor de la dentina remanente en la cavidad, el riesgo de exposición pulpar, la supervivencia odontoblástica y la respuesta dentinogenética del complejo dentino-pulpar.

general, se considera como profunda aquella caries cuya exéresis o excavación completa implicaría la exposición pulpar. Coincidiría con las lesiones de caries que en la radiografía invaden tres cuartas partes o mas del espesor dentinario (19).

Así pues, el criterio clínico a tener en cuenta para realizar la TECE es la presencia de una lesión cariosa que envuelve radiográficamente a más del $75 \%$ de la superficie dentaria y de la dentina, con una zona radiodensa visible y bien definida entre la caries y la pulpa, vitalidad pulpar positiva, ausencia de patología periapical y de episodios anteriores de dolor pulpar provocado o espontáneo, aunque podría plantearse la realización de esta técnica en presencia de dolor provocado leve o moderado.

En la eliminación de la caries dentinaria profunda por etapas, se realiza una primera eliminación del tejido central superficial, necrótico y desmineraliza- do, con excavación completa de la dentina periférica desmineralizada. Se utiliza una cucharilla manual, evitando en todo momento la instrumentación cercana a la pulpa. Se deja la dentina blanda de apariencia húmeda y descolorida en la zona central de la preparación. Sobre ella se coloca hidróxido de calcio como base cavitaria y se sella temporalmente con ionómero de vidrio.

Trascurridas entre 8 y 12 semanas, se vuelve a abrir la cavidad y se realiza la eliminación final de la caries, hasta dejar en la zona central de la lesión una dentina de color amarillento o gris y de consistencia dura. Se vuelve a colocar hidróxido de calcio como base cavitaria y restauramos con material definitivo.

Como puede apreciarse, la TECE es una técnica en muchos aspectos similar al recubrimiento pulpar indirecto (RPI), una técnica conservadora que a día de hoy se viene realizando rutinariamente en la práctica odontológica diaria. La TECE sigue el mismo principio que el RPI, pero es aún más conservadora. En el RPI se realiza directamente una excavación más profunda y minuciosa de la caries, por lo que se corre un mayor riesgo de exposición pulpar. Por el contrario, en la TECE, al realizar la excavación en dos pasos, se disminuye el riesgo de exposición pulpar. Al realizar la segunda apertura se observa como se ha formado una dentina terciaria de color marrón y consistencia dura, por lo que al realizar la eliminación final de la caries disminuye el riesgo de exposición pulpar. De ahí que esta técnica haya sido descrita como solución alternativa al RPI, pues su principal ventaja es el menor riesgo de exposición pulpar, con un elevado porcentaje de curación de la lesión (19).

En el estudio realizado por Bjørndal et al. (20) en el que se compara la TECE con la técnica de eliminación completa de la caries en la primera visita, se obtuvo mayor porcentaje de éxito en aquellos pacientes en los que se realizó la TECE, con un menor riesgo de exposición pulpar.

Uno de los posibles inconvenientes que se han planteado a esta técnica, es la presencia de crecimiento bacteriano al dejar una dentina blanda y desmineralizada durante el período intermedio del tratamiento, y la posibilidad de reactivación de la caries una vez 
finalizado el mismo. Sin embargo, Bjorndal et al. $(21,22)$ demostraron que, si bien los niveles de crecimiento bacteriano tras la primera fase de excavación de la caries, antes de la aplicación del material sellador, eran altos, tras la excavación final de la caries el crecimiento bacteriano era notablemente menor. Por tanto, en la TECE la eliminación final de la caries, la segunda etapa, es de vital importancia para la curación definitiva de la lesión.

La necesidad de un correcto sellado de la restauración, tanto provisional como definitivo, es de vital importancia para el éxito del tratamiento. De lo contrario la aparición de lesiones con presencia de flora microbiana, es claramente observable y por tanto el fracaso del tratamiento.

Estudios recientes han planteado la utilización de gel de clorhexidina o antibióticos (LedermixÒ) como base cavitaria alternativa al hidróxido de calcio, obteniendo en ambos casos resultados que demuestran eficacia en la reducción del crecimiento bacteriano para Streptococos Mutans y Lactobacillus y bacterias anaerobias en general $(23,24)$. No obstante se requieren estudios prospectivos a largo plazo para comprobar la eficacia de la utilización de estas sustancias como bases cavitarias en la TECE.

\section{CONCLUSIONES}

La técnica de eliminación de la caries por etapas ha demostrado ser eficaz en el tratamiento de las caries dentinarias profundas. Al tratarse de una técnica mínimamente invasiva, protege a la pulpa, permitiendo el desarrollo de su actividad dentinogénica, y previene la afectación pulpar intraoperatoria con un menor riesgo de exposición pulpar y de tratamiento de conductos. No obstante, se necesitan estudios prospectivos a más largo plazo para valorar con mayor exactitud su porcentaje de éxito.

\section{BIBLIOGRAFÍA}

1. Segura-Egea JJ, Jiménez Rubio-Manzanares A. Bases moleculares y celulares de la dentinogénesis primaria y secundaria. Arch Odontoestomatol 1999; 2:68-76.
2. Smith AJ. Dentin formation and repair, in: Seltzer and Bender's Dental Pulp, Hargreaves KM, Goodis HD (eds.), Quintessence Publishing Co, Carol Stream, USA, 2002, pp.41-62.

3. Ten Cate AR. Oral histology: Development, Structure and Function. Mosby, St. Louis, 1994.

4. Segura-Egea JJ, Jiménez-Planas A, Llamas R. Participación de las prostaglandinas y leucotrienos en los procesos inflamatorios y reparativos periapicales. Implicaciones endodónticas. Arch Odontoestomatol 1996;12:258-65.

5. Segura-Egea JJ, Jiménez-Rubio A, SánchezBarriga R, Llamas R. Neuropéptidos en la pulpa dental: el péptido intestinal vasoactivo (VIP) y su participación en la fisiopatología pulpoperiapical. Rev Eur Odonto-Estomatol 1996;8: 107-14.

6. Tziafas D. Basic mechanisms of cytodifferentiation and dentinogénesis during dental pulp repair. Int J Dev Biol 1995;39:281-90.

7. Segura-Egea JJ, Jiménez Rubio-Manzanares JJ. Bases moleculares y celulares de la dentinogénesis terciaria reactiva y reparativa. Arch Odontoestomatol 1999;9:381-90.

8. Bjørndal L. The Caries Process and Its Effect on the Pulp: The Science. Is Changing and So Is Our Understanding. J Endod 2008;34:S2-S5.

9. Smith AJ, Cassidy N, Perry H, Begue-Kirn C, Ruch JV, Lesot H. Reactionary dentinogenesis. Int J Dev Biol 1995; 39:273-80

10. Smith AJ Pulpal responses to caries and dental repair. Caries Res. 2002 Jul-Aug;36(4):223-32

11. Yamamura T. Differentiation of pulpal cells and inductive influence of various matrices with reference to pulpal wound healing. J Dent Res 1985;64:530-40.

12. Thysltrup A, Fejerskov O. Textbook of Cariology. Copenhagen: Munksgaard, 1986. 
13. Fusayama T, Okuse K, Hosoda H. Relationship between hardness, discoloration and microbial invasion in carious dentin. J Dent Res 1966; 45: 1033-46.

14. Ivar A. Mjör. Dentin Permeability: The Basis for Understanding Pulp Reactions and Adhesive Technology. Braz Dent J 2009;20(1):3-16.

15. Fusayama Ty Terashima S. Differentiation of two layers of carious dentin by staining. Bull Tokyo Med Dent Univ 1972;19:8392.

16. Ceballos L. Adhesión a dentina afectada por caries y dentina esclerótica. Av. Odontoestomatol 2004;20:71-8.

17. Ricketts DNJ, Kidd EAM, Innes N, Clarkson J. Complete or ultraconservative removal of decayed tissue in unfilled teeth. Cochrane Database Syst Rev 2006;3:CD003808.

18. Miyashita H, Worthington HV, Qualtrough A, Plasschaert A. Pulp management for caries in adults: maintaining pulp vitality. Cochrane Database Syst Rev 2007;2:CD004484.

19. Bjørndal L. Indirect Pulp Therapy and Stepwise Excavation. J Endod 2008; 34:S29-S33.

20. Bjørndal L. Treatment of deep caries lesions in adults: randomized clinical trials comparing stepwise vs. direct complete excavation, and direct pulp capping vs. partial pulpotomy. Eur J Oral Sci 2010;118:290-7.

21. Bjorndal L, Larsen T, Thylstrup A. A clinical and microbiological study of deep carious lesions during stepwise excavation using long treatment intervals. Caries Res 1997;31:411-7.

22. Bjorndal L, Larsen T. Changes in the cultivable flora in deep carious lesions following a stepwise excavation procedure. Caries Res 2000;34:502-8.

23. Wicht MJ, Haak R, Schütt-Gerowitt $H$, Kneist $S$, Noack MJ. Suppression of Caries-Related Microorganisms in Dentine Lesions after ShortTerm Chlorhexidine or Antibiotic Treatment. Caries Res 2004;38:436-41.

24. Ersin NK, Uzel A, Aykut A, Candan U, Eronat C. Inhibition of Cultivable Bacteria by Chlorhexidine Treatment of Dentin Lesions Treated with the ART Technique. Caries Res 2006;40:172-7.

\section{CORRESPONDENCIA}

Dr. Juan J. Segura-Egea

Departamento de Estomatología

Universidad de Sevilla

Avicena, s/n

41009-Sevilla

Correo-e: segurajj@us.es 